\title{
Conditioned suppression of licking as a function of shock Intensity'
}

\author{
J. P. JAMES and WALTER W. MOSTOWAY, University of \\ Manitoba, Winnipeg, Canada
}

An altemative to the operant-response-based CER procedure is described in which suppression of licking behavior in rats provided a measure of the CER. The results indicated that acquisition and resistance to extinction of conditioned suppression of licking varied directly with the intensity of shock used during training. These findings were discussed in relation to similar results reported for conditioned suppression of operant behavior.

Conditioned suppression of lever pressing is a well-established procedure for studying the principles of emotional conditioning (cf. Beecroft, 1967, pp. 50-53). First utilized by Estes \& Skinner (1941) and subsequently standardized by Kamin and his associates (e.g., Annau \& Kamin, 1961), this procedure involves the conditioning of an emotional response (fear) by pairing shock with some neutral stimulus. In the experiments by Kamin, rats are reinforced for lever pressing on a VI 2.5-min schedule during 2-h daily sessions. After operant response rate has stabilized, four trials of CS-shock pairings are presented each day. Since the conditioned emotional response (CER) is assumed to be incompatible with operant responding, the extent to which the Ss refrain from lever pressing during the $3-\mathrm{min}$ CS will provide a measure of the CER.

In the present experiment, instead of using ongoing operant behavior as a base against which the CER is superimposed, acquisition and extinction of the emotional response occurred against a background of consummatory responding, i.e., licking. Although Leaf \& Muller (1965) have used suppression of licking as an indicator of the strength of a CER acquired in a nonlicking situation, their procedure is limited to providing a one-trial test. The present study is analogous to the Kamin procedure in that it provides a trial by trial measure of CER.

Annau \& Kamin (1961) have reported that acquisition and resistance to extinction of an operant-response-based CER are increasing functions of UCS intensity. In the present experiment it was expected that by varying shock intensity, similar functions would be obtained for a consummatory-response-based CER.

Subjects

\section{METHOD}

The Ss were 32 male Holtzman albino rats, either 250 days of age and previously used in a runway study $(\mathrm{N}=16)$ or 90 days of age and experimentally naive $(N=16)$. The $S s$ from each age group were equally represented in each of the shock-intensity conditions.

Apparatus

A modified commercially manufactured conditioning chamber (Scientific Prototype A-100), with the manipulandum and food cup removed, was set in a ventilated, sound-insulated box (Lehigh Valley A-64). Clear Plexiglas windows at the front $(3 \times 5$ in.) and rear $(6 \times 6$ in.) replaced portions of the metal walls. Two $6-\mathrm{W}, 120-\mathrm{V}$ ac incandescent lamps were mounted behind the front windows 6 in. above the grid floor and served as one component of the compound CS. The other component of the CS, white noise of $82 \mathrm{~dB}$, was produced by means of a Grason-Stadler $901 \mathrm{~B}$ noise generator. Continuous illumination was provided by one $6-\mathrm{W}$, $120-\mathrm{V}$ ac lamp located 4 in. above the floor outside the rear window. $A$ $3 \frac{1}{2} \times 2 \frac{1}{2}$ in. patch of black tape was attached in front of the rear lamp and served to reduce the background illumination. The tube of a water bottle $2 \mathrm{in}$. above the floor and $2 \mathrm{in}$. from the right wall protruded into the chamber. The opening at the end of the tube was .15 in. diam. The bottle was filled with fresh tap water. Grid shock was supplied by a Grason-Stadler shock generator (E1064GS). The lick transducer was a Grason-Stadler Drinkometer (E4690A-L). The drinkometer circuit was grounded through the grid floor except during shock presentation when the entire licking circuit was disconnected from the conditioning chamber. Thus, licking could not be recorded during shock presentation. All events were programmed to occur automatically by standard equipment in an adjacent room.

Procedure

The experiment was conducted over 28 successive days. Six days of adaptation to water deprivation and two days of adaptation to the apparatus and to the potential CS were followed by 10 days of acquisition and 10 days of extinction.

Initially, four Ss from each age group were randomly assigned to each of four groups differing in UCS intensity. The intensities of shock used were $0.1,0.5,1.0$, or $2.0 \mathrm{~mA}$ and the shock duration was $0.5 \mathrm{sec}$. The intensity and duration of shock were determined by fixed dial settings on the face of the shock generator. The Ss were housed individually and had continuous access to Purina Lab Chow in the home cage for the entire experiment. All sessions in the conditioning apparatus started with each S's first lick and were of $10-\mathrm{min}$ duration. The tube of the water bottle was continuously available to the $S s$ in the conditioning chamber.

Pretraining consisted of six days of adaptation to a water-deprivation schedule consisting of $20 \mathrm{~min}$ of water bottle availability at the home cage and two subsequent daily adaptation sessions in the conditioning apparatus. Beginning with the first adaptation session in the chamber and continuing for the remainder of the experiment, Ss received their entire daily ration of water in the experimental chamber. During each of the two days of apparatus adaptation, the potential compound $\mathrm{CS}$, light and white noise, was presented 10 times on an alternating 30-sec-on, 30-sec-off, sequence. The number of lick responses produced during the periods of stimulation and silence were recorded on separate counters.

The Ss received one acquisition or extinction trial each day. ${ }^{2}$ The CS onset occurred on different days randomly either 30,60 , or $90 \mathrm{sec}$ after each S's 20th licking response. The duration of the CS was $30 \mathrm{sec}$ and its offset occurred simultaneously with the UCS. The total number of licking responses was recorded on separate counters during each of the following periods: a preCS period starting $30 \mathrm{sec}$ prior to $\mathrm{CS}$ onset, the $\mathrm{CS}$ period, a 30 -sec postCS period starting with CS offset, and the entire $10-\mathrm{min}$ session. With the exception of omitting shock, extinction was conducted in exactly the same manner as acqusition.

Daily suppression ratios during acquisition and extinction were computed by the formula $B /(A+B)$ where $A$ represents the total number of licking responses during the preCS period and $B$ is the total number of licking responses during the period of the CS. The data were analyzed by means of analysis of variance (ANOV) and subsequent Newman-Keuls tests.

\section{RESULTS}

The possibility of differential performance by the two age groups was tested by two separate 2 by 4 ANOVs (Age by Shock Intensity) on the mean suppression ratios for acquisition and extinction. In addition to significant shock intensity effects during both acquisition and extinction (ps $<.001$ ), the younger Ss were found to show faster extinction $(F=5.67, \mathrm{df}=1 / 24$, $p<.05$ ). Since neither of the Age by Shock Intensity interactions for acquisition or extinction was significant, the two age groups were combined for purposes of further analysis. During the two days of adaptation to the conditioning apparatus, there was no difference in the frequency of licking during periods of stimulation and silence $(p>.30)$.

Figure 1 portrays a major finding of the experiment in terms of the effects of shock intensity on the acquisition and extinction of conditioned suppression of licking. The mean suppression ratios for each of the four shock intensity groups are plotted across acquisition (Trials 1-10) and extinction (Trials 11-20).

For acquisition, a 4 by 10 mixed design ANOV (Shock Intensity by Trials) indicated that both main effects and the interaction were significant at $\mathrm{p}<.001$ (Shock Intensity: $F=32.44, \mathrm{df}=3 / 28$; Trials: $F=37.84, \mathrm{df}=9 / 252$; Shock Intensity by Trials interaction: $F=3.23, \mathrm{df}=27 / 252$ ). Shock 


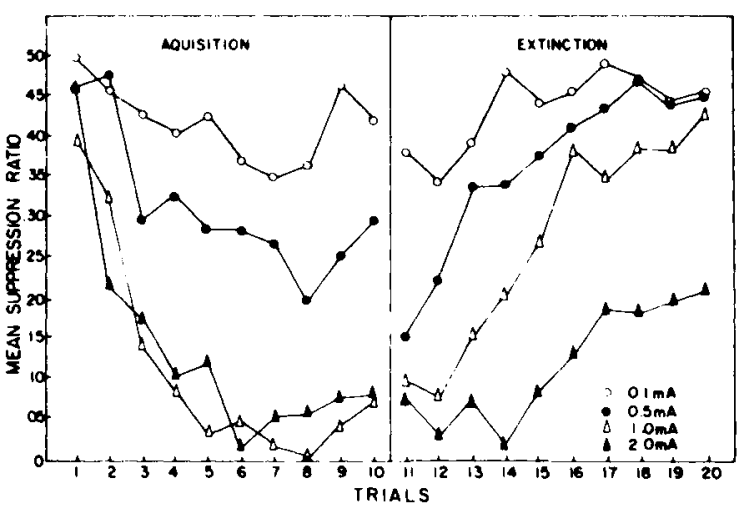

Fig. 1. Mean suppression of licking for the four shock intensity groups across the 20 trials of the experiment (10 acquisition and 10 extinction trials).

Intensity and Trials accounted for $37 \%$ and $17 \%$ of the variance, respectively. Newman-Keuls tests of the four shock intensity groups indicated that with the exception of $1 \mathrm{~mA}$ vs $2 \mathrm{~mA}$, all comparisons were significant $(\mathrm{p}<.01)$. These results are illustrated in the left panel of Fig. I which indicates that mean group performance diverged across trials. The $0.1-\mathrm{mA}$ group showed little conditioning while the 1- and 2-mA groups showed the best performance. The $0.5-\mathrm{mA}$ group exhibited a level of conditioning between that of the lowest and highest shock intensity groups.

A 4 by 10 mixed design ANOV (Shock Intensity by Trials) of the extinction data indicated that both main effects and the interaction were significant (Shock Intensity: $F=36.47$, $\mathrm{df}=3 / 28, \mathrm{p}<.001:$ Trials: $\mathrm{F}=20.83, \mathrm{df}=9 / 252 . \mathrm{p}<.001$ Shock Intensity by Trials interaction: $F=2.15, \mathrm{df}=27 / 252$, $\mathrm{p}<.005 \%$. The amount of variance accounted for by Shock Intensity and Trials was $42 \%$ and $15 \%$, respectively. By Newman-Keuls tests, with the exception of $0.1 \mathrm{~mA}$ vs $0.5 \mathrm{~mA}$, all comparisons between the four levels of Shock Intensity were significant $(\mathrm{p}<.01)$. As is shown in the right panel of Fig. 1 , the $0.1-, 0.5-$, and $1-\mathrm{mA}$ groups show a fairly rapid rate of extinction as compared to the 2-mA group. Although the 1- and 2-mA groups were undifferentiated during acquisition, as extinction progressed the group means tended to diverge with the 2-mA group exhibiting greater resistance to extinction.

To determine whether shock intensity influenced base level licking, Treatment by Trials ( 4 by 10) ANOVs were performed on the number of licking responses during the pre- and postCS periods of acquisition and extinction. During acquisition shock intensity tended to reduce base level responding during both the preCS $(\mathrm{F}=4.98, \mathrm{df}=3 / 28, \mathrm{p}<.01$, accounting for $12 \%$ of the variance $)$ and postCS $(F=6.76, d f=3 / 28, p<.005$, accounting for $11 \%$ of the variance) periods. However, during extinction the training shock intensities served to decrease rate of licking only during the preCS period $(F=7.61, \mathrm{df}=3 / 28, p<.001$, accounting for $16 \%$ of the variance).

The total amount of water consumed during each session is reflected in the total number of licking responses that the Ss produced each day. For acquisition a significant Shock Intensity by Trials interaction $(F=1.91, \mathbf{d f}=27 / 250, p<.01)$ indicates that shock intensity influenced water intake differentially. For the $0.1-\mathrm{mA}$ group a rapid increase in the average water intake to the third day was followed by a gradual decline. The $0.5-\mathrm{mA}$ group showed a gradual increase in its water intake over the 10 days. For the 1 - and 2-mA groups an initial reduction in overall drinking to the third day was folloued by a rapid increase. There appeared to be no group differences in water consumption on Trials $7-10$ of acquisition. During the extinction trials a gradual increment in water intake occurred in all groups $(\mathrm{f}:=3.63$. $\mathrm{df}=8 / 223, \mathrm{p}<.001)$. Total number of licks on the final day of extinction were not recorded. Because of apparatus failure two of the total-response scores during acquisition and one of these scores during ex tinction were lost.

\section{DISCUSSION}

The results of this experiment are strikingly similar to those of Annau \& Kamin ( 1961$)$. Besides the general finding that acquisition and resistance to extinction are increasing monotonic functions of UCS incensity in training. the results of the two experiments agree on several oller points. First, the highest intensity shock groups $(1.0$ and $2.0 \mathrm{~mA})$, which showed the same level of performance during acquisition, did not become differentiated until extinction when resistance to extinction was directly related to shock intensity. Second, there was a semblance of $U$-shaped acquisition curves in all groups, indicating a slight recovery from suppression. Such a curve occurred only in the $.49 \mathrm{~mA}$ group of Annau \& Kamin (1961). Third, responding during the preCS period was inversely related to shock intensity in both studies. In addition, the present study revealed that this decrease in responding persisted into the postCS period only during acquisition.

At this point it is appropriate to briefly comment on the present experimental procedure. To adequately monitor the CER it is important that baseline responding be relatively stable. Pilot studies have suggested that to insure high intrasession licking rates, the $S$ s must receive their entire daily water allowance during the 10 -min experimental sessions. Even with this requirement met, rate of licking is not stable across the session. As the Ss become satiated, there is a tendency for periods of pausing to become more frequent and of longer duration. Such pausing demands that trial presentation occur early in the session when drive is relatively high. The use of variable time intervals between session beginning and trial onset served to militate against the learning of a temporal discrinination of UCS onset.

Solomon (1964) has pointed out that consummatory acts, unlike operant responses, become permanently suppressed by weak or moderate punishment. In the case of conditioned suppression, however, the obtained temporary suppression of consummatory behavior appears to be not unlike that found for operant responses.

The results presented here suggest that a licking-based CER procedure may be a feasible approach to exploring emotional conditioning. It is less time consuming than the standard CER procedure since the Ss are not "shaped" to respond and a daily session is only $10 \mathrm{~min}$ in length. One parameter of the CER, UCS intensity, now appears to produce similar suppressive effects for both operant and consummatory behavior. Further research will indicate whether other variables produce such common effects.

\section{REFERENCES}

ANNAU, Z, \& KAMIN, L. J. The conditioned emotional response as a function of intensity of the US. Journal of Comparative \& Physiological Psychology, 1961, 54, 428-432.

BEECROFT, R. S. Emotional conditioning. Psychonomic Monograph Supplement, 1967, 2, No. 4, (Whole No. 20).

ESTES, W. K., \& SKINNER, B. F. Some quantitative properties of anxiety. Journal of Experimental Psychology, 1941, 29, 390-400.

LEAF, R. C., \& MULLER, S. A. Simple method for CER conditioning and measurement. Psychological Reports, 1965, 17, 211-215.

SOLOMON, R. L. Punishment. American Psychologist, 1964, 19 239-253.

\section{NOTES}

1. This report is based on a part of the data collected by the second author for a Master's thesis. The research was supported by Grant APA-223 from the National Research Council of Canada to the first author.

2. Two trials per day were administered to an additional $32 \mathrm{Ss}$ which otherwise received the same conditions as the $S s$ in this report. In general, the results are similar to those presented here. 